\title{
Vinos y destilados a través de la publicidad. Estrategias de marketing gráfico en Argentina y Chile $(1900-1930) *$
}

\author{
Wines and distillates through advertising. Print marketing strategies in \\ Argentina and Chile (1900-1930)
}

\section{Michelle Lacoste Adunka}

Universidad San Sebastián, Santiago, Chile

mlacosteaddocente.uss.cl

\section{Pablo Lacoste}

Universidad de Santiago de Chile, Santiago, Chile.

pablo.lacostedusach.cl

\section{Resumen}

El artículo analiza el proceso de consolidación de las marcas comerciales europeas de vinos y destilados en Argentina y Chile, a través de la publicidad gráfica del magazine argentino Caras y Caretas, y los chilenos Zigzag y Sucesos, entre 1900 y 1930. Se examina una muestra intencionada en base a su pertinencia significativa compuesta por 26 anuncios. Se identificaron las principales estrategias de las campañas publicitarias: el recurso a la estética del Art Nuveau en el Vino de Burdeos, el Champagne, el Coñac, la Ginebra y el Cinzano, y la apelación a las costumbres de terratenientes ingleses a través del Whisky. Se concluye que las agresivas campañas de publicidad lograron trasladar el valor del consumo estatutario tradicional: origen y territorio de las bebidas alcohólicas, hacia los símbolos de estatus ligados a la cultura de la elite europea, fomentando así una disociación identitaria que sólo recientemente ha comenzado a revertirse.

Palabras clave: Publicidad, Vinos y destilados, Estrategias de Marketing, Magazines.

\begin{abstract}
This article analyzes the consolidation process of European commercial brands of wines and distillates consolidation in Argentina and Chile, through graphic advertising in Argentinian magazine Caras y Caretas and the Chileans Zigzag and Sucesos, between 1900 and 1930. A purposeful sample of 26 advertisements is examined based upon its significant relevance. The main strategies of the advertising campaigns were identified: the recourse to the aesthetics of Art Nuveau in Bordeaux Wine, Champagne, Cognac, Geneva and Cinzano, and the appeal to the customs of English landowners through Whiskey. It is concluded that the aggressive advertising campaigns managed to shift the symbolic value of traditional statuary consumption: origin and territory of alcoholic beverages, towards the status symbols linked to the culture of the European elite, thus promoting an identity dissociation that only in recent dates It has begun to reverse.
\end{abstract}

Keywords: Advertising. Wines and distillates. Marketing Strategies. Magazines.

\footnotetext{
* Este artículo se ha realizado en el marco de la ejecución del proyecto 031894 LG PS 618 “Patrimonio Agroalimentario en Chile Central”, financiado por la Dirección de Investigación Científica y Tecnológica (DICYT) de la Vicerrectoría de Investigación, Desarrollo e Innovación (VRIDEI) de la Universidad de Santiago de Chile.
} 


\section{Introducción}

En el primer tercio del siglo XX, el Cono Sur de América ofreció un creciente mercado a las principales empresas internacionales de vinos y destilados, en el marco del proceso de modernización alimentaria europeizante que fue común a gran parte de las grandes ciudades de América Latina (Palma, 2004; Remedi, 2017). Especialmente en Argentina esto se vio potenciado por la gran inmigración europea, que traía consigo sus hábitos tradicionales de consumo (Lacoste, 2003). Además, la prosperidad económica de Argentina y Chile, debido al boom de las exportaciones de materias primas y la vigencia de los principios del libre comercio, generó un contexto económico favorable para el desembarco de Burdeos de Coustau Fréres, Champagne Louis Roederes y Cognac Frapin y Girard desde Francia, vermouth Cinzano de Italia, ginebra Bols de Holanda y whisky Buchanan's "Black and White" de Escocia, marcas que libraron grandes batallas de diseño y creatividad en las publicaciones masivas de Buenos Aires y Santiago. Si bien también existieron las versiones locales de estos productos europeos (Núñez, 2016), en este trabajo nos centraremos en las campañas publicitarias de las marcas extranjeras, entendiendo que estudiar el consumo es crucial para comprender el fondo de los debates sobre la buena sociedad y la vida buena (Aldridge, 2003).

En este sentido, el artículo rastrea el proceso de consolidación de estas marcas comerciales europeas de vinos y destilados en Argentina y Chile, a través de la publicidad gráfica en los primeros treinta años del siglo XX. De manera complementaria, el estudio ha considerado las estrategias que algunas de las empresas seleccionadas desarrollaban de manera sincrónica en otros mercados, a fin de definir la especificidad de las campañas conosureñas. La pregunta de investigación gira en torno a qué elementos culturales ponía en valor el consumo simbólico de bebidas alcohólicas extranjeras en el mercado del Cono Sur. El marco temporal está definido por el inicio de la publicación de la revista Caras y Caretas en Argentina en 1898, y cierra con la crisis mundial de 1929-1930, que generó profundos cambios en la naturaleza y el volumen del comercio internacional.

Esta investigación se desarrolla en el espacio de convergencia entre la historia de la vitivinicultura y la lucha por el mercado interno entre los productos típicos locales y las bebidas de origen europeo (Lacoste, 2003; Lacoste et al., 2014). El problema se estudia desde el consumo y la publicidad, que a nivel global estaba sufriendo transformaciones profundas, con el marco de fondo de la revolución industrial y las mejoras tecnológicas en el mundo de los medios gráficos, que sentaron las bases para la cultura del consumo (Magaudda, 2015) y, en particular, del consumo estatutario (Veblen, 1899).

Por otro lado, su originalidad radica en que si bien existen varios trabajos sobre el desarrollo y la función cultural de los magazines a inicios del siglo XX en Argentina y Chile (Rogers, 2008; Ossandón, 2002a, 2002b; Ossandón \& Santa Cruz, 2005), éstos no se han detenido específicamente en el análisis de la publicidad de bebidas alcohólicas, con la excepción de un estudio reciente, que aborda el problema en función de las medidas higienistas de la época y no en relación al valor simbólico del consumo de productos extranjeros (Fernández \& Sedran, 2019).

\section{Marco Teórico}

El período comprendido por esta investigación coincide temporalmente con la transformación internacional hacia la cultura del consumo y la cultura de masas (Montero, 2011; Ossandón \& Santa Cruz, 2005), que impactó fuertemente en las tendencias en publicidad (Klein, 2002; Tungate, 2007). Este proceso daría paso a la consolidación de la “publicidad moderna" (Varela, 2017). Es el tiempo de la transición de un capitalismo de libre competencia hacia formas monopolísticas, donde grandes grupos económicos buscaban protegerse de los riesgos de la competencia al posicionarse en situación de dominio (tanto material como simbólico) sobre otras unidades económicas (Sixto, 2010, p. 63). Al mismo tiempo, la persona que hasta mediados del siglo anterior se definía por su condición de ciudadano o súbdito, comenzaba a entenderse como sujeto deseante y, por lo tanto, como sujeto consumidor, y allí se inserta la publicidad, entendida como la divulgación de anuncios de carácter comercial para atraer posibles compradores (González, 1994). 
Con el cambio de centuria, comenzó un proceso de transición en el cual convivía el mensaje racional, a través del texto, con el mensaje emocional, expresado en la imagen. Esta tendencia marcó un cambio radical en la historia de la publicidad, pues a partir de entonces, la corriente principal de las campañas publicitarias se orientó hacia la conexión emocional con el cliente antes que en los argumentos racionales. El Art Nouveau resultaba adecuado por dos motivos: por un lado, el letrero tenía un lugar privilegiado dentro del diseño; se integraba artísticamente con los íconos y la marca escrita, lograba un efecto hasta entonces desconocido para lograr alto nivel de visibilidad y recordación.

Por otra parte, al minimizar el fondo y el paisaje para realzar la figura (Afanador, 2007, p. 20) y reemplazarlo por formas orgánicas y motivos vegetales (Silverman, 1992), este estilo lograba desprender el producto de su origen territorial. Todo ello era particularmente funcional a los objetivos de las grandes empresas que tenían, como meta central, el fortalecimiento de sus marcas comerciales, en detrimento de los territorios y los campesinos que habían creado originalmente los productos. Fue una época de intuición y libertad creativa, en la cual se sentaron las bases para el desarrollo posterior a escala global de elementos clave, como el desarrollo de la imagen de marca, iniciado en la década de 1940 (Klein, 2002).

En este marco, el artículo analiza las diversas estrategias de marketing, a las que recurrieron las marcas estudiadas, en el marco de la renovación estética del diseño gráfico. Estas campañas acogieron la propuesta estilística del Art Nouveau, y utilizaron como medios preferidos los afiches en la vía pública y los anuncios gráficos en los magazines, que también atravesaban entonces un ciclo de auge, con la incorporación de tecnologías capaces de publicar ilustraciones masivamente.

Surgían entonces publicaciones como Caras y Caretas en Buenos Aires y Sucesos y ZigZag en Chile. Sus bajos precios debido a la financiación de los anuncios comerciales (Rogers, 2008) y su variado despliegue gráfico los convirtieron en medios masivos de comunicación sin antecedentes, funcionales al desarrollo de la "industria cultural" y el mercado cultural moderno (Ossandón, 2002a, p. 164). A comienzos del siglo XX, el tiraje de Caras y Caretas superaba los 100.000 ejemplares por semana. De hecho, fue catalogada como "un verdadero prisma que permite ver el surgimiento del mundo moderno en la Argentina" (Varela, 2017, p. 65).

La difusión masiva de estos magazines aseguraba la alta visibilidad de sus anuncios comerciales, por lo que las grandes empresas internacionales invirtieron en ellas sus recursos publicitarios. En varios casos, se realizaban las matrices en Europa y luego se trasladaban a los países donde se exportaban y consumían los productos. Esta economía de escala permitía bajar los costos y obtener así ventajas comparativas sobre sus competidoras locales. Esto facilitó que las empresas estudiadas lideraran la profunda renovación de la publicidad gráfica y su masificación en el Cono Sur, en el campo de los vinos y destilados.

\section{Marco Metodológico}

A fin de analizar la trayectoria de las estrategias de publicidad utilizadas por las principales marcas de vinos y destilados extranjeros en el Cono Sur, se desarrolló un análisis cualitativo diacrónico y sincrónico, al revisar lo números editados entre 1898 y 1930 de Caras y Caretas (desde el número 1 al 1630); los números 1 a 783 de Sucesos (entre 1902 y 1917) y los números $1-45$; 64-358 y $372-462$ de ZigZag ${ }^{1}$. Estos magazines fueron seleccionadas en base a criterios de alcance de reconocimiento, circulación y continuidad temporal de la publicación, así como de accesibilidad. Caras y Caretas fue el magazine emblemático del mercado argentino (Rogers, 2008; Fernández \& Sedrán, 2019) y ZigZag fue la más exitosa en Chile (Ossandón, 2002a).

El universo de la muestra de anuncios sobre los que se trabajó fueron todos aquellos anuncios relativos a bebidas alcohólicas extranjeras publicitadas en cualquiera de los tres magazines mencionados. A partir de allí, se tomó una muestra intencionada en base a su pertinencia significativa (Otzen \& Manterola, 2017) de 26 anuncios, a fin de comprender el desarrollo diacrónico y sincrónico de las diversas estrategias de marketing en función de los valores vinculados con el consumo simbólico, dado que se trató en todos los casos de bienes de lujo publicitados a las élites y a las masas. 
Una vez realizado el trabajo heurístico de recolección de datos, los anuncios encontrados fueron clasificados en categorías construidas en base a la naturaleza del producto anunciado y las principales estrategias verbales y gráficas utilizadas a lo largo del tiempo. Asimismo, la muestra fue estudiada a través de la técnica de análisis de discurso ISayago, 2014), atendiendo a los argumentos vinculados al valor simbólico asociado de forma estable del consumo del bien publicitado, la cual es una de las principales herramientas de la publicidad (Ferraz, 1993, p. 10).

El marco interpretativo de los anuncios tuvo en cuenta la propuesta teórica de "el Gran Recomendador" que se refiere a la estrategia utilizada cuando "se delega la voz (en la publicidad) para figurar un tipo de enunciador que construye discursivamente el ethos de un presentador (...) basa su efectividad en el ejercicio de la influencia" (Suárez, 2019 , p.37). Según el autor, esta influencia puede ser intelectual, cuando apela al conocimiento, o afectiva, cuando utiliza el miedo, el deseo o la esperanza del público. Estudiar cuál es el "Gran Recomendador" permite detectar qué sistemas de valores busca utilizar cada marca para persuadir al consumidor potencial.

Cabe señalar, además, que cada anuncio analizado en el presente trabajo presenta en su epígrafe el soporte de dónde se extrajo originalmente y la fecha. No obstante, es importante destacar que Cinzano hacía publicidad en los tres magazines estudiados con interesantes vínculos bilaterales. El champagne se anuncia tanto en Caras y Caretas como en Zigzag. Los anuncios de Ginebra Bols, Vino Burdeos y Spumante italiano son del mercado argentino; y los de Congnac Frapin y Whisky Buchanan's aparecen en los magazines chilenos.

\section{Análisis}

\subsection{Los vinos de Burdeos y su liderazgo en la publicidad Art Nouveau}

La poderosa industria vitivinícola de Burdeos lideró el desembarco del Art Nouveau en la publicidad de vinos y destilados en el Cono Sur de América. En 1906, las casas importadoras comenzaron a in- cluir cartelería impregnada con las características de este estilo en Buenos Aires. Impactantes carteles se difundieron a través de los magazines, que promocionaban estos vinos con imágenes de mujeres en pose seductora con pámpanos y racimos de uva.

Los anuncios de vinos de Burdeos representaban las características clásicas del Art Nouveau europeo, en su variante orgánica y naturalista. Se destacaban con claridad las formas orgánicas y la actitud de regreso a la naturaleza. La propuesta dialogaba con la estética específica del mundo del vino y los paisajes de viñedos, con la profusión de pámpanos, zarcillos, hojas de parra y racimos de uva. La evocación de la mujer, como diosa de la abundancia, se integraba al mensaje comercial del vino. La publicidad de estos vinos comenzaba a distanciarse del lugar de producción, con la esforzada vida del viticultor, para avanzar hacia el espacio de la fantasía, la imagen de prestigio y la vida atractiva, asociada a la mujer joven y presentada en una pose que connota un estereotipo de seducción.

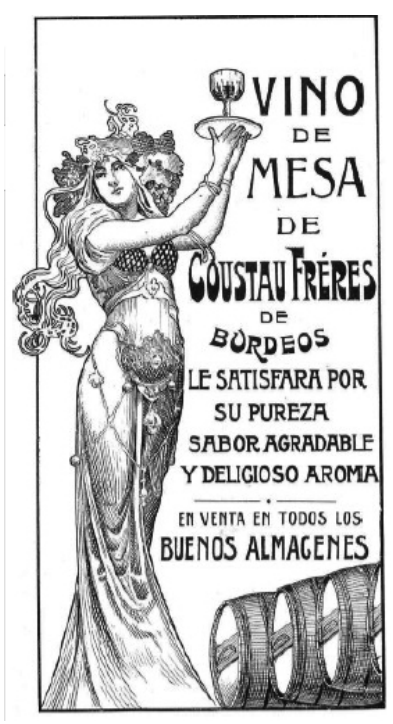

Imagen 1. Vino Coustau Fréres. Fuente: Caras y Caretas $n^{\circ}$ 406/7: 14 y 21-7-1906.
En cuanto al texto de la publicidad, llama la atención que el principal argumento de venta en el aviso hace referencia a la "pureza del vino" o al tratarse de "vino francés de pura uva". Este argumento cobra sentido al considerar la crisis de la Filoxera, que generó el florecimiento de vinos adulterados y falsificados, tanto en el mercado como en los manuales de vitivinicultura que circulaban en el Cono Sur (Lacoste, 2017) 


\subsection{Champagne y Espumante.}

Las campañas de Champagne francés Louis Roederer aplicaron la técnica del grabado con fuerte inspiración del Art Nouveau, incluyendo la ausencia de volumen, la simplificación de líneas y los motivos orgánicos. Pero el elemento más logrado en este diseño es la plena integración del área icónica con el área tipográfica; las palabras formaban parte activa de la composición. El aviso publicado en Caras y Caretas en víspera de las fiestas de $\mathrm{Na}$ vidad y Año Nuevo de 1923 es un buen ejemplo.

Las campañas publicitarias del champagne, igual que las de vino de Burdeos, desplazaban el interés del producto del paisaje vitivinícola del campesino y la viña, hacia el mundo del deseo, el placer de los sentidos y el estatus social. La mujer es presentada en pose seductora, con trajes livianos que exhibían cuello, hombros y brazos. El producto se separaba del productor y se convertía en un bien de consumo, con fuertes connotaciones simbólicas, donde lo principal eran las sensaciones. El producto tenía un fuerte valor simbólico y ofrecía establecer un vínculo entre el consumidor y su objeto de deseo. Además, ganaba relevancia la marca dentro del espacio total del afiche. Poco a poco, se daban los primeros pasos para vincular la marca con la imagen de prestigio.

Otro ejemplo es el anuncio publicado en la revista ZigZag en 1913. El mensaje no sólo indica a través del texto que se trata de un "champagne aristocrático", sino que utiliza estrategias de composición propias del arte moderno. No aparece la clásica figura humana completa, sino que a través del simbolismo de la múltiples copas, se destaca la única que recibe esta bebida. La mano que sostiene la copa lleva ropas elegantes.

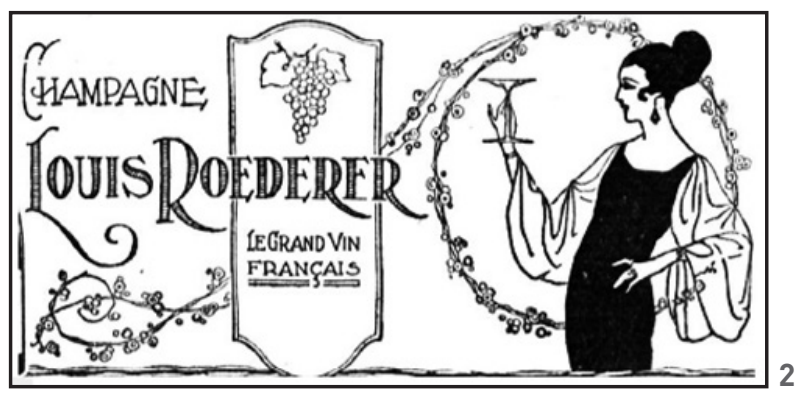

La estrategia del espumante italiano adoptó un camino diferente. Si bien desde el punto de vista del tema, también se apoyaba en la figura de la mujer; en vez de mostrarla con ropas modernas, los italianos la arrobaban con vestidos tradicionales. La mujer representaba a la campesina italiana, con sus trajes típicos y su canasta donde portaba la uva recién cosechada, por lo que tenían un mayor anclaje con el paisaje del vino. No obstante, con clara inspiración estética en la obra de Aubrey Breardley, se ponía el énfasis en el uso de las líneas curvas para las grandes faldas. Las dimensiones de los vestidos exhibían la voluntad de diferenciarse de la sufrida vida cotidiana de la vendimia, pero se rescataban los elementos propios del campo para integrarse con estética de la mujer de alto rango social, propia del salón y el banquete, espacio del consumo estatutario.

\subsection{Vermouth Cinzano y su impacto visual}

Si bien se ha detectado presencia del vermouth italiano en Chile desde la década de 1880 (Couyoumdjian, 2006, p.54), fue a comienzos del siglo XX cuando este brebaje, junto con el espumante de Italia, se lanzó a la conquista de los mercados conosureños con fuertes inversiones publicitarias. Sus campañas promocionales causaron un fuerte impacto porque las empresas aprovecharon las fortalezas de creativos y diseñadores italianos. A ello se sumó la decisión de desarrollar diseños acorde a la propuesta del Art Nouveau.

Las campañas de Cinzano utilizaron tanto ilustraciones realizadas por artistas de renombre como
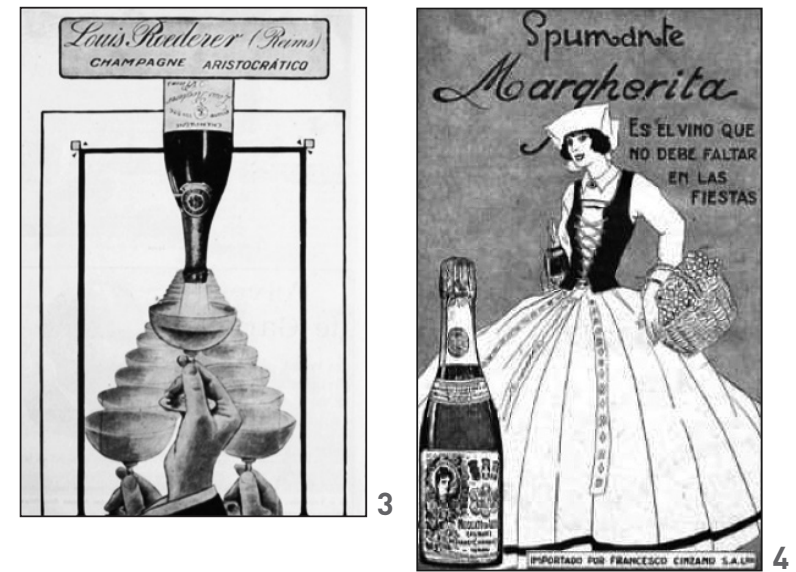
Guido Petiti, que circulaban en la publicidad de la marca a nivel internacional, como ilustraciones más simples y sin firma, donde la fuerza estaba en el mensaje escrito.

Las campañas de Cinzano utilizaron elementos del movimiento Art Nouveau para desarrollar gráficamente dos líneas conceptuales para vincular emocionalmente el producto con el consumidor: el producto como herramienta de construcción de masculinidad y como medio de seducción y conquista. Los mensajes orientados a asociar el Cinzano con la identidad masculina representaban la bebida con un hombre vestido según la moda de la élite y rodeado de mobiliario elegante. El anuncio se resolvía en líneas simples y esbeltas. El consumidor de Cinzano se distinguía por su juventud y elegancia, a diferencia del cliente de Oporto, Jerez y Cognac, vinculados a la vejez.

Por otro lado, en la publicidad de Cinzano en Chile también se apelaba a la relación entre el producto y la juventud, de una manera aún más directa.

La otra línea conceptual de Cinzano, daba un lugar de relevancia a la mujer, a la vez que fortalecía la identificación del producto como reafirmante de la identidad masculina. Por lo general, la figura del varón tenía un papel más activo: estaba de pie, junto a la mujer sentada; levantaba la copa para brindar, mientras la mujer bebía y asumía una postura más relajada; en todos los casos, la botella de Cinzano estaba más cerca del varón. Desde el punto de vista estético, predominaban las líneas curvas, representadas por los pliegues del mantel, el vestido de la mujer y la postura de los personajes.
En cuanto al mensaje asociado a la ilustración, Cinzano también apeló al "Gran Recomendador", como se puede observar en los anuncios publicados en Chile, que hacen referencia a las preferencias de argentinas y argentinos por el producto. Luego, se optó por equiparar a consumidoras con sus pares trasandinas, cuando pregonaba ser la preferida por "chilenas y argentinas".

Las campañas de Cinzano, tanto en Chile como en Argentina, fueron un temprano experimento de construcción de imagen de marca. Como se ha señalado, estos conceptos se desarrollarían en profundidad a partir de la década de 1940. No obstante, un análisis de los sucesivos avisos de Cinzano muestran un temprano avance en esa dirección. Fueron constantes en presentar la marca, en un entorno atractivo, vinculada a los valores del éxito social, la seducción y el prestigio.

Imagen 2. Champagne Louis Roederer.

Fuente: Caras y Caretas n 1315/6: 15/22-12-1923

Imagen 3. Champange Aristocrático.

Fuente: Zig Zag 455, 15-12-1913.

Imagen 4. Spumante Margherita.

Fuente: Caras y Caretas n 1421: 26-12-1925

Imagen 5. Cinzano de Petiti.

Fuente: Zig Zag nº 432: 31-5-1913

Imagen 6. Cinzano varón.

Fuente: Caras y Caretas n 1.054: 14-12-1918

Imagen 7. Cinzano ¿Cuántas veces este pícaro me ha hecho ovlidar mis años?

Fuente: Zig Zag 377, 11 de mayo de 1912.

Imagen 8. Cinzano pareja.

Fuente: Caras y Caretas nº 1213: 31-12-1921
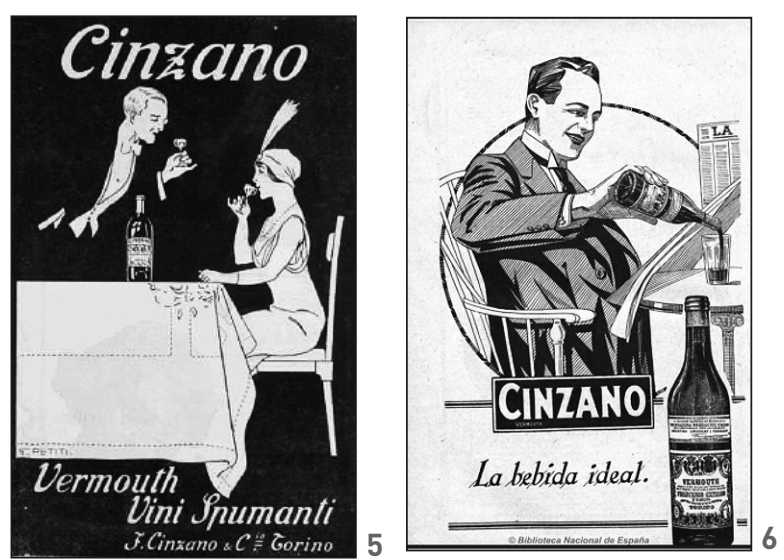

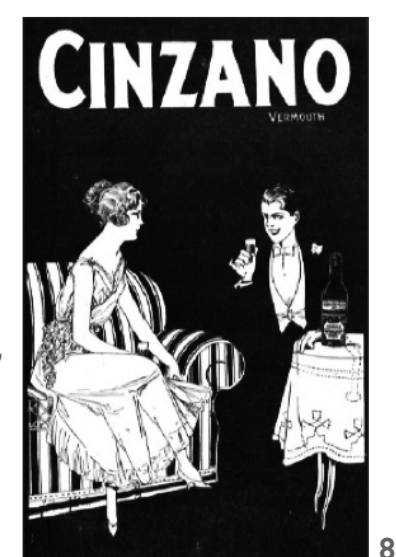




\subsection{Tiempos de Cognac}

Tras la apertura comercial de mediados del siglo XIX, el cognac francés llegó a los mercados del Cono Sur y libró una intensa batalla comercial para desalojar a las aguardientes locales. Las élites conectaron rápidamente, pues les permitía afirmar su posición privilegiada. Consumir cognac era una forma de pertenecer a los círculos distinguidos de la sociedad, con sus lazos reales o pretendidos con la prestigiosa Francia.

La publicidad de cognac realizaba la idea de Toulouse Lautrec, en el sentido de incorporar el campo gráfico con el icónico. Las letras se integraban plenamente en el diseño del total del aviso: los títulos eran parte de la imagen, la ambientación se eliminaba o reducía al mínimo, a la vez que las relaciones métricas realistas se abandonaban. Se destacaban también amplias líneas monocromas y los contrastes acusados, propios de la aplicación del Art Nouveau en la publicidad conosureña de la época (Steimberg \& Traversa, 1997, p. 57).

Dentro las campañas publicitarias del cognac, se detectan dos líneas: por un lado, se reutilizaron ilustraciones elaboradas para el mercado internacional. Por otro, se aprovechó el arte de los ilustradores locales, a través de anuncios elaborados específicamente para el mercado local.

La marca Cognac Frapin utilizó la misma ilustración adaptada al nuevo formato, pero firmada por
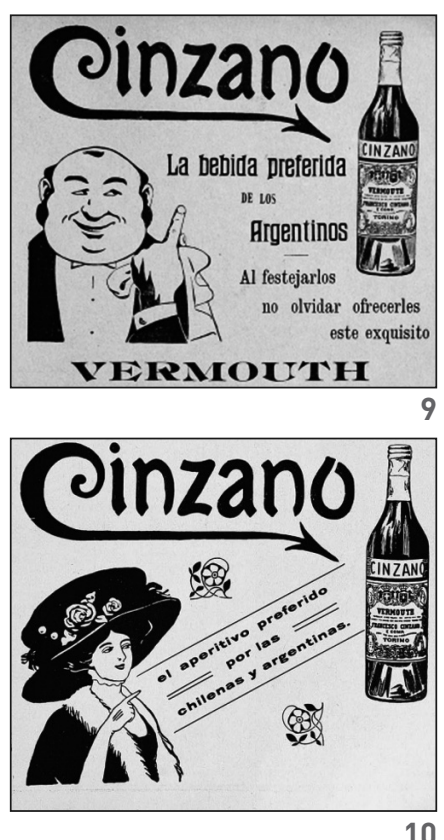

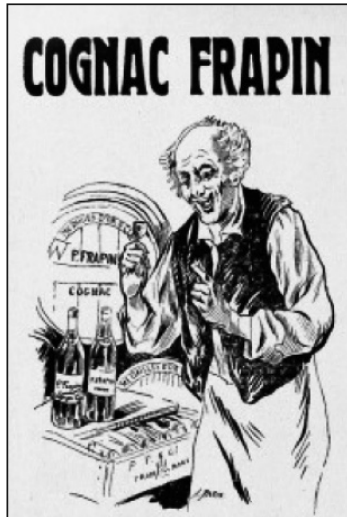

ESTE SI QUE ES BUENOO...!
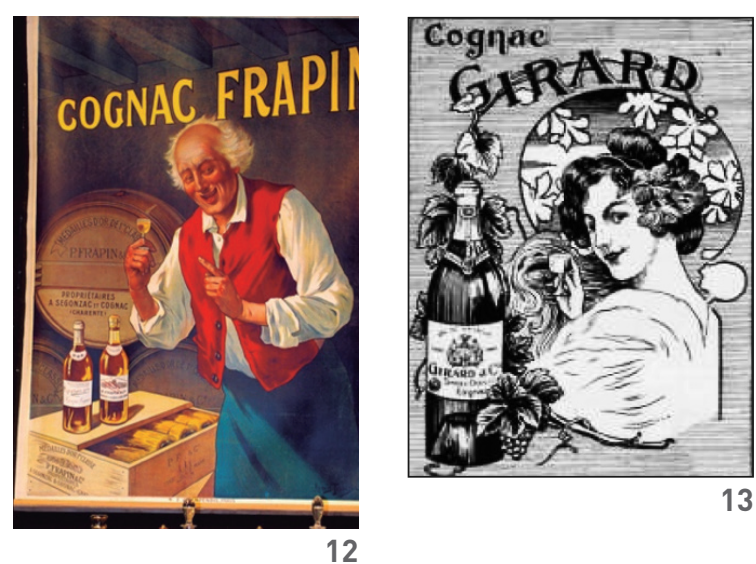

el mismo artista, Louis Tanzin, tal como se puede apreciar a continuación.

Mientras tanto, Cognac Girard utilizó para una publicidad en Argentina en 1913, una ilustración que circulaba en Alemania desde 1904 en forma de estampilla ${ }^{3}$.

Por otro lado, la marca Cognac Frapin aprovechó el espacio de la "Caricatura Semanal" ofrecido para publicidad por la revista ZigZag en 1912 y 1913 , donde se presentaba una ilustración elaborada localmente en tamaño de página completa en el dorso de la portada de la revista, inspirada fuertemente en las propuestas de Aubrey Beardsley, con sus diseños en colores naranja y blanco. En este caso es interesante el texto que acompaña las ilustraciones. En el anuncio de 1912, se hace referencia a que el Cognac Frapin era el Cognac de los Reyes, y el anuncio señala "pues a mí me da la real gana hoy de ser Rey". Por lo tanto, el consumo del producto no se asocia simplemente a los usos y costumbres de la aristocracia, sino que al de la realeza.

Por otro lado, el siguiente anuncio de 1913 hace referencia a las cualidades del Cognac Frapin, que le han dado su fama mundial: "su exquisito gusto, calidad digestiva y antigüedad", y vincula la fama del producto al sujeto representado en la ilustración, el dramaturgo Daniel de la Vega, a quien la revista le desea "igual suerte". En este caso, el "Gran Recomendador" no sería el consumidor, 
sino el producto en sí mismo, cuyo renombre se utiliza para impulsar la carrera del artista.

\subsection{Espíritu de Holanda: ginebra Bols}

La inversión publicitaria de Ginebra Bols se destacaba por la originalidad de sus diseños y los espacios privilegiados que contrataba: varios años compraron el retiro de tapa de Caras y Caretas para sus campañas. La tendencia general apuntaba a vincular el producto con valores universales. A diferencia de los productos de Francia, España, Portugal y Gran Bretaña, los holandeses evitaban el nacionalismo y la proyección de sus valores y cultura. Esta tendencia era consistente con la tradición eminentemente comercial del imperio holandés, y fue respetada por ginebra Bols. De hecho, las campañas de la marca se caracterizan por haber sido especialmente elaboradas para el mercado argentino.

La estética propuesta de las campañas de Bols apuntaba a vincular el producto con una visión global de mundo. El grabado de 1915 representaba botellas de ginebra como grandes columnas del mundo, capaces de sostener los cables que representaban la transmisión de la energía, símbolo del Progreso. Por su parte, el dibujo de 1910 apuntaba a destacar un atributo específico de la ginebra Bols: su vejez, acreditada por las telas de araña. En ambos casos, se detectan detalles estilísticos de carácter decorativo, con predominio de líneas curvas y formas simples. En las tres décadas de avisos publicitarios que impulsó ginebra Bols, este tipo de avisos cosmopolitas fueron los más recurrentes.

Igual que el Cinzano italiano, Bols realizó en el Cono Sur un temprano proceso de construcción de imagen de marca. En ambos casos, la palabra con la marca ocupaba un lugar importante en los avisos; se usaba el mismo tipo de letra, para asegurar

Imagen 9. Cinzano argentinos.

Fuente: Sucesos no 418: 7-9-1910

Imagen 10. Cinzano chilenas y argentinas.

Fuente: Sucesos No 435: 5-1-1911

Imagen 11. Cognac Frapin.

Fuente: Sucesos n ${ }^{4} 46$ : 23-3-1911.

Imagen 12. Cognac Frapin

Fuente: National Geographic².

Imagen 13. Cognac Girard.

Fuente: Zig Zag n 455-457: 8, 15 y 22-12-1913.

Imagen 14. Cognac Frapin reyes.

Fuente: Zig Zag nº 379: 125-05-1912.

Imagen 15. Cognac Frapin. Daniel de la Vega.

Fuente: Zig Zag n 456: 15-11-1913.

Imagen 16. Bols Comunicaciones.

Fuente: Caras y Caretas n 899: 25-12-1915

Imagen 17. Bols telaraña.

Fuente: Caras y Caretas n 638: 24-12-1910
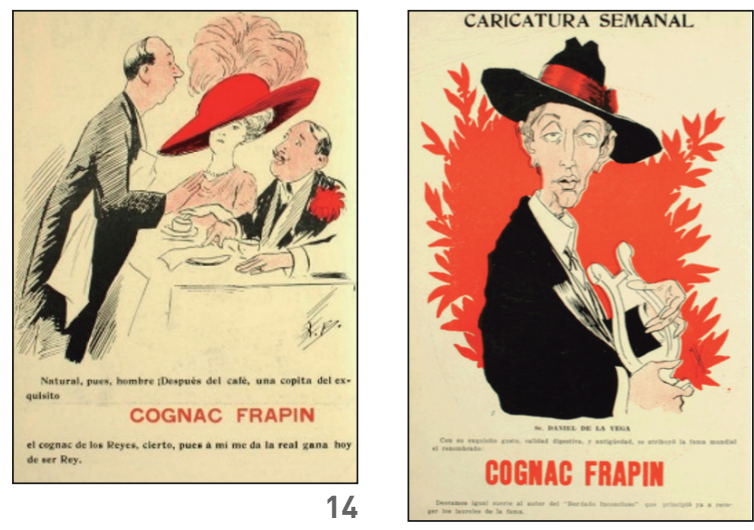

15
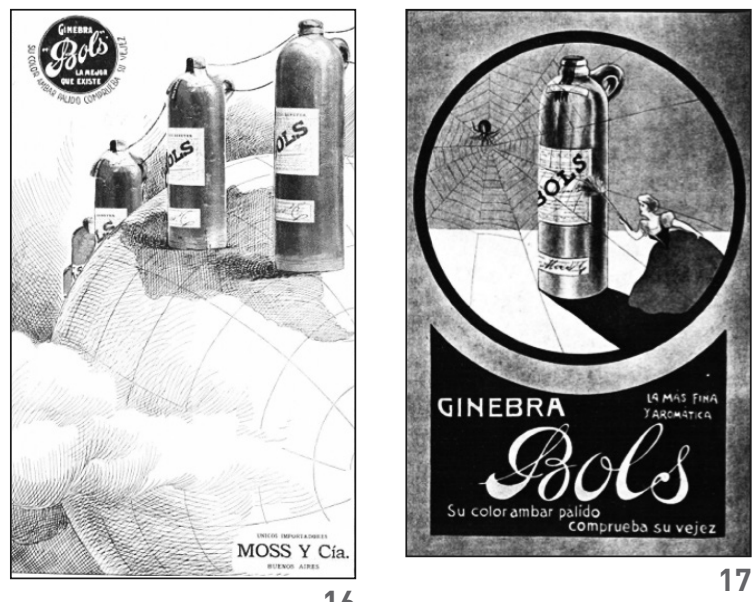
la continuidad y la persistencia en la memoria del público. Además, lentamente, la marca avanzaba desde el producto (cada vez menos importante) hacia las imágenes y los modos de vida. En ambos casos se hablaba muy poco del enebro, la enebrina y las campiñas italianas; en su lugar, surgían imágenes que prometían atractivos estilos de vida, libre y cosmopolita.

De todos modos, este movimiento no fue lineal. En la década de 1920 , se produjo un giro transitorio en la estrategia comercial de ginebra Bols. La empresa procuró construir lazos con sus clientes con evocaciones a la cultura argentina, tanto en los salones de alta sociedad, con lo que se acercó a las campañas del Champagne y el Cinzano, como en el medio rural, a partir del gaucho.

La campaña gauchesca de ginebra Bols fue un golpe publicitario extraordinario que rompía totalmente los moldes de la rigurosa estrategia de marketing de las bebidas importadas. Al parecer, los holandeses de Bols comenzaron a detectar tempranamente que el prestigio de los imperios occidentales comenzaba a declinar a partir de la I Guerra Mundial y, en su lugar, soplaban vientos identitarios, que se reflejaban en nuevos movimientos culturales, como el criollismo y la gauchesca, cada vez más fuertes en el Cono Sur. Estas tendencias se entroncaban también con la crisis del paradigma de la confianza en el progreso eurocéntrico, y el auge de los movimientos de resistencia nacionalista, promovidos en Argentina por Leopoldo Lugones y Ricardo Rojas (Maiz, 2002).

La etapa del nacionalismo holandés de ginebra Bols se desarrolló también en este periodo. Fue en 1923 cuando, en forma paralela al ciclo de publi- cidad gauchesca, la empresa lanzó una campaña para valorizar el producto a partir de la visibilización de la cultura material de Holanda. Por primera vez se publicó en forma masiva, a través de los medios de prensa, los símbolos específicos de los Países Bajos, incluyendo los molinos, los personajes típicos como niños, campesinas y marineros con indumentaria tradicional: abrigos, sombreros y zapatos.

En la representación de las mujeres holandesas con sus vestidos típicos, los diseñadores aplicaron una vez más el repertorio formal del Art Nouveau, incluyendo el predominio de las líneas curvas, la renuncia al volumen, los fuertes contrastes negro/ blanco y la actitud decorativa, pero la protagonista se representaba junto a los clásicos molinos, con sus sombreros y zapatos típicos.

Las campañas publicitarias avanzaban así hacia nuevos códigos de comunicación visual, que requerían identificar los elementos propios de cada cultura, visibilizarlos y representarlos de formas sencillas y claras, fuertemente contrastadas y de fácil comprensión. El mensaje se independizaba cada vez más de la naturaleza del producto. La invisibilización de la enebrina, columna vertebral de la identidad de la ginebra holandesa, fue un símbolo de este cambio. En su lugar, se desarrollaban imágenes como medio para construir un vínculo emocional con el consumidor. El objetivo principal era vincular de alguna manera la marca al prestigio. Ya fuera el de la modernidad industrial, de la cultura holandesa y sus mujeres y marinos, o de la visión romántica del gaucho. Se estaba poniendo en marcha una nueva estrategia para conquistar públicos masivos, lo cual no se había conocido antes en el sur de América.

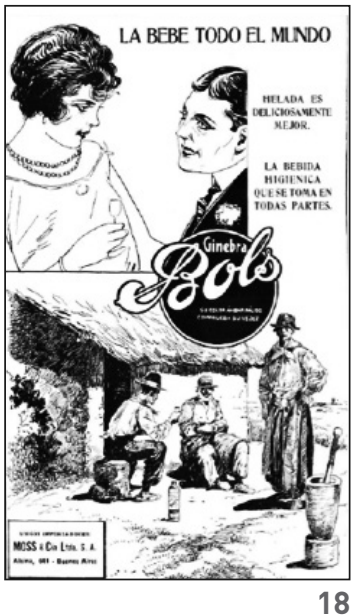

18

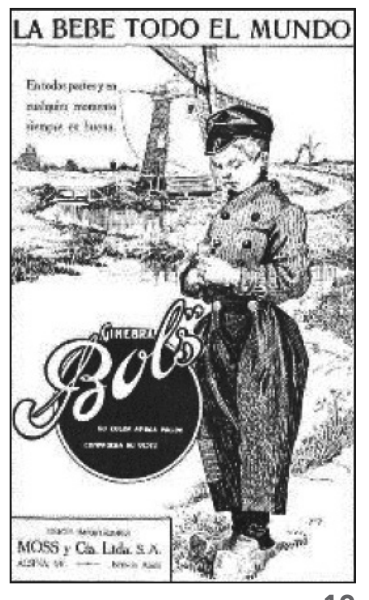

19

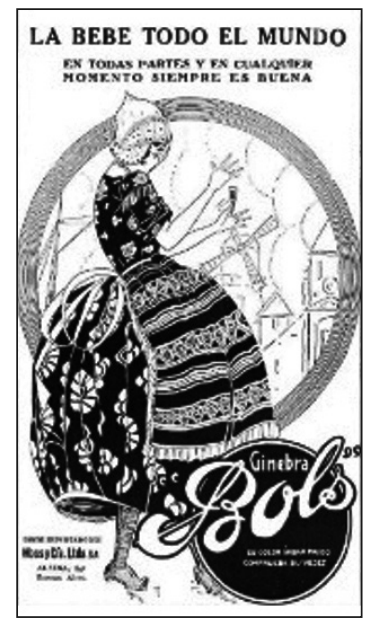




\subsection{Whisky escocés para el terrateniente sudamericano}

Las campañas más representativas de whisky en esta región fueron impulsadas por la empresa Buchanan's, cuya primera destilería surgió en 1894 en Escocia. Su marca más conocida fue "Black and White", asociada en la actualidad a dos perros de raza fina. Sin embargo, esta imagen se consolidaría recién en la década de 1920 . Antes, la marca experimentó una constante evolución y búsqueda de sus emblemas corporativos a través de un proceso de prueba y error, el cual se reflejó en las campañas publicitarias del Cono Sur de América, y especialmente en Chile, donde utilizaron las ilustraciones que la empresa presentaba en el extranjero. De hecho, este es el caso que presenta un mayor vínculo con las campañas publicitarias que hacía la marca en el resto del mundo. En un primer momento las publicidades se importaron directamente al escenario local, sin siquiera traducir el texto, tal como se puede apreciar en la imagen del anuncio publicado en Sucesos de 1909.

En otros casos, se utilizaba la misma ilustración, aunque cambiando o suprimiendo el texto vinculado a ella, como en la publicidad de 1907 que es exactamente la misma utilizada en un anuncio de 1906 en Inglaterra 4 .

Las campañas publicitarias de whisky apelaban a símbolos cercanos a los terratenientes: el mundo de los caballos y los perros de caza. El whisky parecía armonizar perfectamente con esta escenografía, lo mismo que su expresión deportiva, representada por el jugador de polo, cuya imagen

fue utilizada para la campaña de whisky, tanto en el cono sur como en otras regiones. De hecho, la ilustración del jugador de polo a caballo utilizada en una publicidad de 1909 en la revista Sucesos fue reutilizada en una campaña gráfica de la misma marca en Inglaterra en $1924^{5}$.

Por otro lado, las campañas de whisky utilizaron también la figura del perro. Los perros acompañaban a los aristócratas en el deporte de los reyes: la caza. En ello participaban perros de caza mayor y perros "de pluma" o de caza menor. Los avisos publicitarios de Black and White incluían representaciones de perros de plumas como el Setter Irlandés, y de perros de caza mayor como Greyhound $^{6}$, y hasta del San Bernardo, tal como se puede apreciar en el anuncio publicado en la revista ZigZag en 1912.

Imagen 18. Bols Gauchesca y salón. Fuente: Caras y Caretas, 1274, 3/3/1923.

Imagen 19. Bols niño holandés.

Fuente: Caras y Caretas n 1274: 3-3-1923

Imagen 20. Bols Holandesa.

Fuente: Caras y Caretas n 1341: 14-6-1924

Imagen 21. Buchanan`s special.

Fuente: Sucesos n 344: 8-4-1909

Imagen 22. Perros de caza mayor.

Fuente: Sucesos n 274 y 277: 5 y 26-12-1907; n 388 102-1910.

Imagen 23. Jugador de polo.

Sucesos no 350: 20-5-1909; n 355: 24-6-1909; n 357: 8-7-1909.

Imagen 24. Buchanan San Bernardo.

Fuente: Zig Zag n 375 : 27-4-1912.

Imagen 25. Buchanan Perros ratoneros.

Fuente: Zig Zag n 392. 24-8-1912.

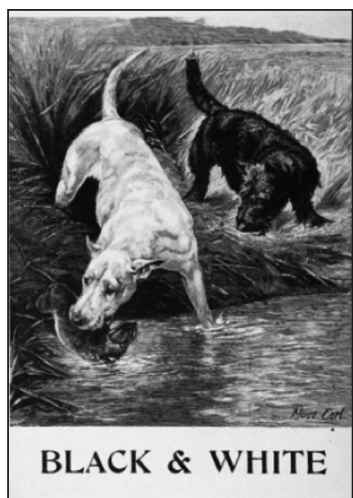

22

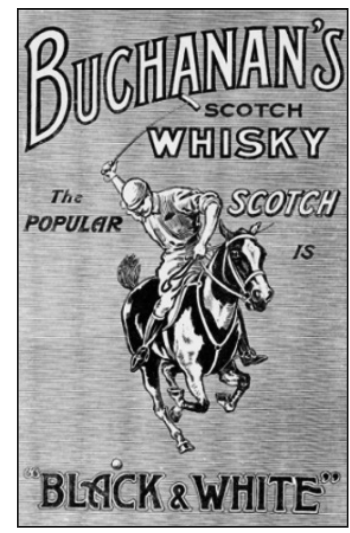

23

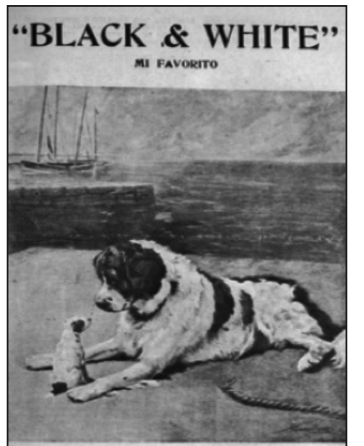

WHISKY BUCHANAN

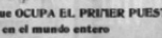
con e mento enters J. Tusche \& Co. $\pi$ valparasso

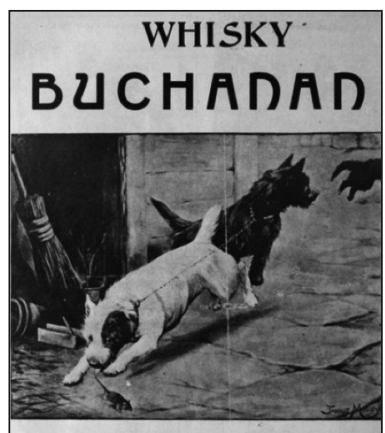

"BLACK \& WHITE" 
Junto con los perros de caza, las campañas originales de la marca incluían representaciones de perros ratoneros. Este era otro código compartido entre terratenientes. A fin de controlar la presencia de roedores, la tradición del campo ha valorado al perro ratonero, entre los cuales uno de los más prestigiosos ha sido tradicionalmente el Fox Terrier y el Schnauzer alemán. Estos fueron justamente los perros que eligió "Black and White" para sus campañas publicitarias en el Cono Sur de América y en el mundo.

El conjunto de caballos de polo y perros cazadores permitía a los creativos de las campañas publicitarias del whisky crear un mundo de fantasía, con elementos de exclusividad, para despertar el interés de los clientes. El producto se convertía así en objeto del deseo, símbolo de ascenso social y lugar donde pocos podían llegar, tal como versa una de las publicidades analizadas: "El whisky favorito de los Sportsmen y de la Alta sociedad en todo el mundo". La imagen del destilado se desprendía del objeto en sí mismo, para transformarse en un símbolo de preeminencia social.

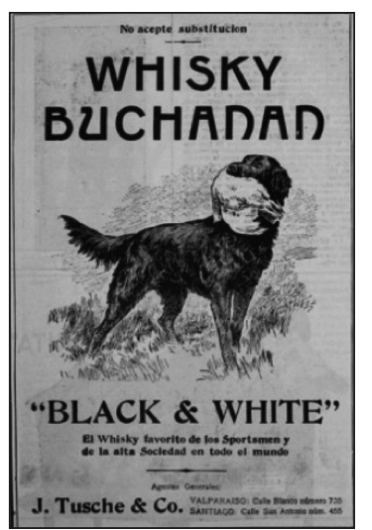

Imagen 26. Buchanan. Perro de plumas. Fuente: Zig Zag n 426: 19-4-1913.

\section{Conclusiones}

Las grandes empresas europeas de vinos y destilados aprovecharon la oportunidad que ofrecían los prósperos y abiertos mercados conosureños, y la avanzada tecnología de sus medios masivos de comunicación gráfica en el marco del desarrollo de la industria cultural para librar grandes batallas de arte, comunicación y diseño. Los magazines de Buenos Aires y Santiago se convirtieron en el escenario privilegiado de este proceso. Las campañas publicitarias utilizaron con intensidad los principios del Art Nouveau, especialmente el uso de la línea curva, la renuncia al volumen y la integración del campo gráfico con el campo simbólico. Con estos elementos, los avisos lograban fuerte impacto en el público y contribuían a sentar las bases para el futuro desarrollo de las grandes marcas de vinos y destilados.

A partir de los casos estudiados, se ha podido detectar que varias de las marcas estaban en proceso de consolidación de campañas publicitarias globales, lo cual no había sido detectado hasta ahora por la bibliografía especializada. Los mismos anuncios que circulaban en las revistas de Inglaterra o Italia se utilizaban en el Cono Sur. En algunos casos ni siquiera se traducía el texto vinculado a la ilustración, lo que ha sido particularmente evidente en el caso del Wiskhy Buchanan's Black and White. En general, estas publicidades buscaban vincular al consumidor con los sportmen, la realeza o los usos y costumbres de Europa, ya que esto traía un prestigio asociado al consumo suntuario de las élites desde la segunda mitad del siglo XIX.

No obstante, hubo excepciones, como Bols. Esta marca holandesa fue fiel al estilo nacional de no imponer la cultura y el idioma, al ser una de las primeras en adoptar símbolos locales para posicionar su producto. El slogan de la marca dejó de ser "la mejor que existe" para afirmar que "la bebe todo el mundo", con lo que buscó desligarse del concepto de bien de consumo exclusivo para las elites. Por otro lado, la marca Cinzano apeló a los consumidores y consumidoras argentinos como "Gran Recomendador" ante el mercado chileno. De todos modos, ambas estrategias buscaban vincular el producto a experiencias y momentos agradables y fueron dejando de lado las características propias de la identidad del producto. 
Si bien existen fuertes lazos sincrónicos en el desarrollo de los anuncios publicitarios de bebidas alcohólicas extranjeras en los magazines de Argentina y Chile, también se han detectado algunas divergencias. Se detecta mayor autonomía en Caras y Caretas reflejada en mayor creación de avisos propios con dibujantes y diseñadores locales: el caso de la Ginebra Bols es emblemático en este sentido. En cambio, en Chile, se observa mayor tendencia a presentar avisos utilizados en Europa y Estados Unidos, especialmente en el caso de Buchanan's. Una explicación de esta asimetría puede ser la diferencia de escala. El mercado interno argentino, potenciado por la gran inmigración de fines del siglo XIX, generaba condiciones de posibilidad para una mayor autonomía creativa, donde dibujantes podían ser contratados tanto por Caras y Caretas como por las marcas que buscaban posicionarse en el mercado.

En todo caso, la resultante final del proceso muestra un alejamiento del valor simbólico ligado a la identidad del producto, para enfocarse en el consumo estatutario, a través de símbolos de estilo de vida y preeminencia social. La ginebra se olvidó de la planta del enebro e invisibilizó la enebrina; el whisky hizo lo mismo con la cebada. Desaparecieron también los esforzados campesinos y viticultores, junto con sus paisajes de viñas. En su lugar, los creativos colocaron flexibles pámpanos y zarcillos; y el sacrificado cosechador se reemplazó con la figura femenina elegante y en pose seductora. La propuesta de las campañas comerciales no era conocer el mundo de la vid y el vino en sus orígenes, con sus paisajes culturales, sus plantas y sus tradiciones campesinas. La industria del marketing y la publicidad cortaba los antiguos lazos de solidaridad entre el productor y el consumidor, entre el campesino y el citadino. Entre ellos emergía, invisible, el poder de los grandes comerciantes y los diseñadores gráficos, encargadas de construir símbolos y mensajes para las masas que veían a las elites escenificadas en los magazines y aspiraban a compartir sus hábitos de consumo.

El vino y los destilados se desprendían de su origen campesino y se alojaban en un mundo imaginario, elegantemente embellecido por el talento de los artistas y diseñadores, rodeado de imágenes de prestigio social. Se ponía en marcha, así, el ciclo de predominio de la marca sobre el territorio.

\section{Notas}

1 Los volúmenes consultados de la revista Caras y Caretas están disponibles en el sitio de la Hemeroteca Digital de la Biblioteca Nacional de España, y los volúmenes consultados de Sucesos y Zigzag están disponibles en el sitio Memoria Chilena.

2 Revisado el 15 de enero de 2019 en https://www. nationalgeographic.com.es/viajes/grandes-reportajes/ visita-al-corazon-de-francia-por-la-ruta-delconac-2_7992/3

3 Se puede observar la imagen en la colección de Alamy: Image ID: BAANP3. https://www.alamy.com/ stock-photo-advertising-stamps-girard-cognacgermany-circa-1910-additional-rights.

4 La imagen se puede observar en la colección Alamy, Image ID: KKKYNO. https://www.alamy.com/stockimage-1906-uk-magazine-buchanans-black-whitewhisky-advert-167010620.html?

5 La imagen de la publicidad puede observarse en la base de datos de Alamay: Image ID: KKNP9T. https:// www.alamy.com/stock-image-1924-uk-magazinebuchanans-black-white-whisky-advert-167050292.html

6 Estos perros también aparecen en las publicidades de la marca en el extranjero, como en el caso del anuncio de 1922 en Inglaterra. Consultar en Alamy, Image ID KKKYG5. https://www.alamy.com/stock-image1922-uk-magazine-buchanans-black-white-whiskyadvert-167010485.html? 


\section{Referencias}

Afanador, L. (2007). Henri de Toulouse Lautrec. La obsesión por la belleza. Bogotá: Panamericana Editorial.

Aldridge, A. (2003). Consumption. Polity Key Concepts the Social Sciences Series. Oxford: Polity Press.

Couyoumdjian, J. (2006). Vinos en Chile desde la independencia hasta el fin de la Belle Époque. Instituto Historia. PUCCh, Historia, 39 (1), 23-64.

Fernández, S. \& Sedran, P. (2019). Consumo respetable: publicidades del alcohol en la Provincia de Santa Fe a inicios del siglo XX. Anuario Colombiano de Historia Social y de la Cultura, 46 (2), 209-235.

Ferraz, A. (1993). El lenguaje de la publicidad. Cuadernos de Lengua Española. Madrid: Arco/libros.

González, M. Á.(1994). Curso de publicidad. Madrid: Editorial Eresma y Celeste Ediciones.

Klein, N. (2002). No logo. El poder de las marcas. España: Paidós.

Lacoste, M. (2017). El convento y el vino: la vitivinicultura en la Recoleta Dominica en el Siglo XIX. Santiago: Colecciones Digitales, Subdirección de Investigación, Dibam. www.bibliotecadominica.cl/678/w3-article-79135.html

Lacoste, P. (2003). El vino del inmigrante: los inmigrantes europeos y la industria vitivinícola. Mendoza: Consejo Empresario de Mendoza.

Lacoste, P., Jímenez, D., Briones, F., Castro, A., Rendón, B. \& Jeffs, J. (2014). Burdeos de Talca y Champagne de Mendoza: Denominaciones de Origen y contaminación identitaria de vinos en Argentina y Chile. Mundo Agrario, 15 (28). 1-25.

Magaudda, P. (2015). The History of Consumer Culture, en Cook, D.T. \& Ryan, J. (ed.) Encyclopedia of Consumption and Consumer Studies. New York: Wiley-Blackwell, pp. 1-7.

Maiz, C. (2002). La Argentina de fiesta. El discurso literario frente al Centenario. Un punto de fuga. América. Cahiers du CRICCAL, 28 (2), 209-217.

Montero, M. (2011). La Publicidad española en el primer ensayo de sociedad de consumo (1920-1936) Un enfoque histórico. Sphera Pública, 11, 351-368.

Núñez, E. (2016). El paradigma europeo en la industria de vinos y licores en Chile: oporto, jerez y cognac hecho en la empresa Mitjans. RIVAR, 3 (9), 123-138.

Ossandón, C. (2002a). ZigZag o la imagen como gozo. Mapocho, 51, 219-234.

Ossandón, C. (2002b). Los inicios de la "cultura de masas" en Chile. Historia y Comunicación Social, 7 (7), 161-168.

Ossandón, C. \& Santa Cruz, E. (2005). Estallido de las Formas: Chile en los albores de la "cultura de masas". Santiago: LOM.

Otzen, T. \& Manterola, C. (2017). Técnicas de Muestreo sobre una Población a Estudio. International Journal of Morphology, 35(1), 227-232. https://dx.doi.org/10.4067/ S0717-95022017000100037 
Palma, D. (2004). De apetitos y de cañas. El consumo de alimentos y bebidas en Santiago a fines del siglo XIX. Historia (Santiago), 37 (2), 391-417. DOI: http://dx.doi. org/10.4067/S0717-71942004000200005.

Remedi, F. J. (2017). Modernidad alimentaria y afrancesamiento. Ciudad de Córdoba (Argentinal en el tránsito del siglo XIX al XX. Historia Crítica, 65, 71-92. doi: dx.doi. org/10.7440/histcrit65.2017.04

Rogers, G. (2008). Caras y Caretas. Cultura, política y espectáculo en los inicios del siglo XX argentino. La Plata: Universidad Nacional de La Plata.

Sayago, S. (2014). El análisis del discurso como técnica de investigación cualitativa y cuantitativa en las ciencias sociales. Cinta Moebio, 49, 1-10.

Silverman, D. (1992). Art Nouveau in fin de siécle France. Politics, Psychology and style. Berkeley: University of California Press.

Sixto, J. (2010). El Marketing y su origen a la orientación social: desde la perspectiva económica a la social. Los aspectos de organización y comunicación. Em Questao, Porto Alegre, (16) 1, 61-77.

Steimberg, 0. \& Traversa, 0. (1997). "Para una historia del lenguaje gráfico argentino". En: VVAA, Estilo de época y comunicación mediática. Buenos Aires: Editorial Atuel, pp. 33-74.

Suárez, B. (2019). Beber o no beber. Particularidades en la construcción del dispositivo enunciativo en el discurso publicitario de cervezas. RIVAR, (6) 16, 31-48.

Tungate, M. (2007) Adland, A Global History of Advertising. London and Philadelphia: Kogan Page.

Varela, G. (2017). La Guerra de las Imágenes. Una historia visual de la Argentina. Buenos Aires: Ariel Historia.

Veblen, T. (1899- 2014) Teoría de la Clase ociosa. Madrid: Alianza Editorial.

- Sobre los autores:

Michelle Lacoste Adunka es profesora de Historia (UNCUYO), magíster en Estudios Internacionales (USACH), y actualmente cursa el doctorado en Historia (UC). Es profesora de la Universidad San Sebastián. Especializada en historia de las relaciones económicas internacionales de América Latina.

Pablo Lacoste es doctor en Historia (UBA) y doctor en Estudios Americanos (USACH), profesor titular de la Universidad de Santiago de Chile. 'Especializado en historia socioeconómica de América Latina, con particular referencia al patrimonio agroalimentario.

- ¿Como citar?

Lacoste Adunka, M. \& Lacoste, P. (2019). Vinos y destilados a través de la publicidad. Estrategias de marketing gráfico en Argentina y Chile (1900-1930). Comunicación y Medios, (40), 42-55. 